Pre-print of full paper presented at CONVERSATIONS 2019 - an international workshop on chatbot research, November19-20, Amsterdam, the Netherlands. The final version of the paper will be published in the post-workshop proceedings as part of Springer LNCS.

\title{
Exploring Age Differences in Motivations for and Acceptance of Chatbot Communication in a Customer Service Context
}

\author{
Margot J. van der Goot ${ }^{1[0000-0001-6904-6515]}$ and Tyler Pilgrim ${ }^{2}$ \\ ${ }^{1}$ Amsterdam School of Communication Research (ASCoR), Nieuwe Achtergracht 166, 1018 \\ WV Amsterdam, the Netherlands \\ $\mathrm{m} \cdot \mathrm{j} \cdot \mathrm{vandergoot@uva \cdot nl}$ \\ ${ }^{2}$ MessageBird, Trompenburgstraat 2C, 1079 TX Amsterdam, the Netherlands
}

\begin{abstract}
This qualitative interview study explores age differences in perceptions of chatbot communication in a customer service context. Socioemotional selectivity theory and research into technology acceptance suggest that older adults may differ from younger adults in motivations to use chatbots, and in perceived complexity and security of this chatbot communication. The in-depth interviews with older adults $(54-81$ years; $\mathrm{N}=7)$ and younger adults $(19-30$ years; $\mathrm{N}=7$ ) revealed that both groups were aligned in their prime motivation: They used chatbots to get their (simple) customer queries answered in a fast and convenient manner. However, they seemed to differ in their need for additional human contact. In both age groups, there were participants for whom it was easy to communicate with chatbots, and the two groups were united in their frustrations when the chatbot did not understand and answer their queries. They were aligned as well in the difficulty they experienced in assessing the security of the chatbot. The two age groups may differ in the factors that contribute to perceived ease of use and perceived security. Directions for future research and implications for the implementation of chatbots for customer service are discussed.
\end{abstract}

Keywords: Chatbots, Customer service, Age differences, Qualitative Interview Study; Older Adults; Motivations; Technology Acceptance

\section{Introduction}

Chatbots, or disembodied conversational agents [2], are increasingly used in customer service: Customers can type their questions in a dialogue screen and receive answers in natural language. Chatbots for customer service are still an emerging technology [7]. For companies it is important that customers of all ages are satisfied with the chatbot conversations, or at least do not feel alienated from the company due to the implementation of chatbot communication.

Based on previous research in other areas, there are two important reasons to suspect there may be age differences in perceptions of chatbot communication. First, socioemotional selectivity theory (SST) [5] outlines how motivations and social pref- 
erences change as people age. Consequently, older adults may also differ from younger adults in their motivations to use chatbots. Second, research in the field of technology acceptance indicates that perceived ease of use and perceived security of several technologies are not the same for older versus younger adults $[8,14]$, which implies that there also may be age differences in perceptions of chatbot communication. Therefore, the aim of the current qualitative interview study is to explore whether older adults (54-81 years) and younger adults (19-30 years) differ in their motivations to use chatbots in a customer service context, and in perceived ease of use and perceived security of this chatbot communication.

This qualitative study contributes to our understanding whether and how age differences should be taken into account in future studies on chatbot communication, and whether SST [5, 19] and models focusing on technology acceptance [4] are useful frameworks for this line of research. Moreover, the study helps practitioners -who are involved in chatbot implementation- to understand whether older customers have a unique set of motivations and needs that should be accommodated for in age-specific ways.

\section{Background}

\subsection{Motivations}

Applying uses and gratifications theory, Brandtzaeg and Følstad studied the motivations for chatbot use among 16-55 year olds. They found that productivity was the main reason for using chatbots: Participants mainly used them to obtain assistance or information, and noted chatbots' ease, speed and convenience. Other motivations included entertainment, social or relational purposes, and novelty/curiosity [3].

We argue that research on the development of motivations across the lifespan suggests that age groups may differ in the prevalence and specifications of the aforementioned motivations for chatbot use. A theory on motivational changes that has been particularly influential in gerontological research is socioemotional selectivity theory (SST) [5]. SST outlines that there are fundamentally two goal categories: knowledgerelated goals and emotionally-meaningful goals [5]. These two categories tend to switch in prominence as people perceive their lifespans to become more finite. Carstensen argues that young adults seek activities that lead to more knowledge acquisition, whereas older adults seek activities that provide an emotional reward. Since this theory concerns socioemotional selectivity, it offers an explanation of reduced rates of interaction in later life: As adults go through their life, their social circles become smaller, because ageing individuals start to value and seek more meaningful social interactions, while younger adults cast a wider social net for the benefit of gaining more information.

The current paper assumes that SST can be relevant for research into chatbot use, since chatbot communication is a type of dialogical communication that resembles social interaction. Applying SST, we could expect that the information-related motivations (part of the main motivation identified by Brandtzaeg and Følstad) would be more prevalent among younger customers, whereas the social and relational motiva- 
tions [3] would be more essential for older adults. In addition, the diminishing of social circles identified in SST research could imply that ageing individuals lack the motivation to use chatbots, instead relying on friends or family to help them with their customer support needs, or preferring human customer service agents over chatbot communication.

Since applying SST to chatbot communication is novel and the potential expectations regarding age differences in this domain are merely speculative at this point, we conducted a qualitative interview study to answer the following research question:

RQ1: How do older and younger adults differ in their motivations to use chatbots in a customer service context?

\subsection{Technology Acceptance}

Models of technology acceptance, such as the Technology Acceptance Model (TAM) and extensions thereof, outline a number of factors that impact technology adoption $[4,11]$. Perceived ease of use and perceived usefulness are central in these models [11]. In the present study, perceived usefulness is addressed in our first research question. Perceived ease of use is also important in the comparison between older and younger adults. After their review of TAM literature, Marangunić and Granić concluded that older adults are a target group of specific interest as age plays a major role in the interaction with technology [11]. A focus group study in which older adults discussed their use of and attitudes regarding technology in the context of home, work, and healthcare found that particularly perceived ease of use (and usefulness) were related to their technology adoption [14]. Due to this previously found association between age and technology use, and the importance of ease of use for older adults, the present interview study sets out to describe potential age differences in perceived ease of use of chatbot communication.

One other aspect where age differences may be particularly at play is perceived security of a new technology. An interview study on trust in chatbots in customer service found that perceived security is one of the factors that affects this trust [7]. The abovementioned focus group study among older adults revealed that older adults often noted security considerations as a reason they disliked using technology, ultimately impacting their technology acceptance [14]. Moreover, previous studies found that older users lagged behind younger users in expertise regarding (internet) security hazards [8]. Thus, on the one hand, perceived security may be of particular importance for older adults, whereas on the other hand they may be less aware of security risks.

In sum, age differences in perceived ease of use and perceived security of chatbot communication in a customer service context can be expected, but are this point merely suggestions that have not yet been subjected to empirical scrutiny. Therefore the second research question is:

RQ2: How do older and younger adults differ in perceived ease of use and perceived security of chatbot communication in a customer service context? 


\section{Method}

\subsection{Sample composition}

Interviews were conducted among two distinct age groups. The older group $(\mathrm{N}=7)$ consisted of adults aged 54-81 years, because businesses typically consider consumers aged above 50 or 55 years as older consumers [13] and because in related experimental research the older adults were also aged 52 or 53 years and older $[10,16]$. The sample consisted of five women and two men. They lived in various regions in the United States. Education was varied, ranging from high school to post doctorate level. The younger group consisted of adults aged 19-30 years, with three women and four men. Three participants in this group lived in the Netherlands and four participants lived in the United States. Education in this group varied from high school to master's degree level. Except for the 81-year old lady, all participants had previous experience with using chatbots.

\subsection{Interviews}

The study was approved by the Ethics Review Board of our university. The second author asked people in his personal network whether they were willing to be interviewed, and he also solicited on Facebook. He conducted the three interviews in the Netherlands face-to-face, and the interviews with participants from the United States through video chat via Google Hangouts. All interviews were conducted in English, and participants signed a consent form prior to the interview.

During the interviews, participants communicated with two chatbots for customer service. They could choose the chatbots of Amtrak, Macy's, or Verizon. In the faceto-face interviews, participants could also choose the bots of Hipmunk, Kayak, KLM, or Tommy Hilfiger. Thus we gathered perceptions regarding chatbots that were used by various types of companies, and that were also varied in human-like features. Once the chatbot connected to a live agent or the participant said the conversation was finished, the interviewer started asking questions.

The interview guide consisted of four topics. Topic 1 aimed to tap into the participant's experiences with this specific chat. It started with an open-ended question: "Please share with me all your experiences during this chat". Subsequently they were shown a blobtree (blobtree.com), and asked to explain which character(s) best described their experiences during the chat. They were also asked how their perception of the chat (potentially) related to their perception of the company. Topic 2 explored their technology acceptance. They were asked what they (dis)liked about the chat, and what they found easy or difficult. They were also asked to rate the complexity, reliability and security of the chatbot (on a scale $1-10$ ), and to explain the rating. Topic 3 was about their motivations. They were asked to explain why they would use this chatbot in the future again (or not), what they expected from the bot, and whether these expectations were met. Topic 4 asked them to reflect more broadly on the use- 
fulness of chatbots for customer service, and whether they thought a chatbot was useful for only certain questions or certain companies.

\subsection{Data Analysis}

Interviews were transcribed verbatim and uploaded in the computer program Atlas.ti. The second author conducted the open coding, a procedure commonly used as the first step in the Grounded Theory Approach [6], that enables the researcher to study the materials in a fine-grained and detailed manner. Subsequently, the second author suggested several possible categorizations that could help to present the findings. After several rounds of discussion and adjusting, the authors decided on a categorization, presented in three tables in a previous version of this paper. Following the advice of reviewers, we decided to merge some of the categories, which resulted in the categorization presented below.

\section{$4 \quad$ Results}

In this section, we answer the two research questions. The findings are displayed in tables, by presenting quotes that exemplify each category. Frequencies refer to the amount of older versus younger participants that mentioned a certain aspect and are merely provided as an illustration of what we encountered in the interviews. These frequencies should be interpreted with caution, because of the small sample sizes and because we asked very open-ended questions (which means that participants may not have spontaneously expressed a certain perception, but would indicate that this perception applies to them when asked about this directly).

\subsection{Age Differences in Motivations}

Regarding RQ1 about age differences in motivations, we found that both age groups were aligned in that their prime motivation was to get their customer query answered (see Table 1). In both groups, some participants specified that bots are mainly useful for simple "black and white" questions, in areas such as e-commerce (for instance when one has questions about the shipping of products), technical support, banking, travel and government, and for scheduling appointments. Participants in both groups acknowledged that for more complex, urgent or personal questions (including health and medical issues), it may be better to talk to a person than to a chatbot. In our sample, there was only one interviewee (P13, 54 years) who did not see chatbots as useful for getting questions answered. She was angry about this type of machines that take up her valuable time and have no clue what she is talking about. She only used chatbots to be connected to a live agent.

Also, most interviewees in both groups applauded the ability to receive answers in a fast, easy, and convenient way. Specific advantages were that chatbots enable them to avoid long phone waits, help them to navigate the company's website, and that interviewees were able to multitask while communicating with a chatbot. 
However, a difference between the two age groups seemed to be their assessment of the human factor. In our sample, older individuals seemed more inclined to use chatbot communication as a stepping stone for human contact (i.e. to connect to a live agent), whereas younger interviewees were more insisting that chatbot communication helps to avoid human contact. This may signal that older adults value human contact more than younger adults.

Table 1. Motivations for using a chatbot for customer service

\begin{tabular}{|c|c|c|}
\hline & Older adults & Younger adults \\
\hline \multirow[t]{2}{*}{$\begin{array}{l}\text { To get an answer to a } \\
\text { customer query }\end{array}$} & $\begin{array}{l}n=6 \\
\text { "Well, to get an answer" (P12, } \\
81 \text { years) }\end{array}$ & $\begin{array}{l}n=7 \\
\text { "I expected that he gave me a fast an- } \\
\text { swer to my problem. And to fix it" (P3, } \\
19 \text { years) }\end{array}$ \\
\hline & $\begin{array}{l}\text { "I would use it for a simple } \\
\text { problem, a single simple prob- } \\
\text { lem. I would not use it for a } \\
\text { complex problem or a problem } \\
\text { with multiple elements to it" } \\
\text { (P9, } 67 \text { years) }\end{array}$ & $\begin{array}{l}\text { "It's kind of like an FAQ where you can } \\
\text { just like type in your question and an- } \\
\text { swer it. I definitely find them to be } \\
\text { useful in that aspect but anything more } \\
\text { complex I think it's a little harder for } \\
\text { them" (P4, } 30 \text { years) }\end{array}$ \\
\hline \multirow[t]{4}{*}{$\begin{array}{l}\text { Ease, speed, and conven- } \\
\text { ience }\end{array}$} & $\begin{array}{l}n=6 \\
\text { "Quick, easy, succinct. Saves } \\
\text { time" (P11, 65 years) }\end{array}$ & $\begin{array}{l}n=7 \\
\text { "It's super-fast and convenient" (P2, } 30 \\
\text { years) }\end{array}$ \\
\hline & $\begin{array}{l}\text { "I think they are useful to avoid } \\
\text { long phone waits" (P9, } 67 \text { years) }\end{array}$ & $\begin{array}{l}\text { "We all know how annoying it is to call } \\
\text { the company [...] and they leave you on } \\
\text { the wait for five six minutes" (P1, } 28\end{array}$ \\
\hline & $\begin{array}{l}\text { "Because I would say there's a } \\
\text { lot of times when I'm internet } \\
\text { shopping for example and I can't } \\
\text { find something and I know it's } \\
\text { there [...]. But the website keeps } \\
\text { coming back saying no. [...]. So } \\
\text { that's when I typically will open } \\
\text { the assistance thing and say help } \\
\text { me" (P10,62 years) }\end{array}$ & $\begin{array}{l}\text { years) } \\
\text { "It feels like an easier way to navigate } \\
\text { their help center without actually like } \\
\text { going through and searching through a } \\
\text { bunch of articles" (P5, } 29 \text { years) "I can } \\
\text { multitask. I can feed the baby and I can } \\
\text { ask the question" (P7, } 27 \text { years) }\end{array}$ \\
\hline & $\begin{array}{l}\text { "Kind of allows me to do other } \\
\text { stuff while I'm working on the } \\
\text { chatbox. You know, like multi- } \\
\text { tasking"(P8, } 60 \text { years) }\end{array}$ & \\
\hline $\begin{array}{l}\text { To connect to a human } \\
\text { agent }\end{array}$ & $\begin{array}{l}n=3 \\
\text { "The only thing I liked about it } \\
\text { was eventually I got to speak to } \\
\text { an actual human being" (P13, } 54 \\
\text { years) }\end{array}$ & $\begin{array}{l}n=1 \\
\text { Interviewer: What was your favorite part } \\
\text { of this one?" "That it offered the option } \\
\text { to talk to a live agent" (P6, } 29 \text { years) }\end{array}$ \\
\hline $\begin{array}{l}\text { To avoid interacting with } \\
\text { a human being }\end{array}$ & $n=0$ & $\begin{array}{l}n=5 \\
\text { "Sometimes when you're interacting } \\
\text { with humans you have to be friendly. } \\
\text { You have to be polite and. Maybe you } \\
\text { had the worst day in your life when you } \\
\text { still have to be polite whereas a chatbot } \\
\text { you're like. You don't have to pretend or } \\
\text { act in a way that you don't want. You } \\
\text { can just be yourself be natural in the }\end{array}$ \\
\hline
\end{tabular}


mood that you are" (P1, 28 years)

"I don't like talking on the phone" (P5, 29 years)

\subsection{Age Differences in Technology Acceptance}

Regarding perceived ease of use, we found that in both age groups there were interviewees who expressed that it was easy for them to use the chatbots. Table 2 shows what they said was easy for them. First, some interviewees provided the overall evaluation that it was clear to them how it worked. Second, some commented more specifically on the smooth interaction. In the older group one of the interviewees applauded the writing style used in the conversation. In the younger group, interviewees noted that the interaction resembled talking to a person or using other devices, and that it was likeable that the chatbot asked for feedback. Third, a specific issue of interest regarding the design of chatbots is the use of preloaded options, i.e. buttons. Several interviewees said that the availablity of such buttons helped the conversation.

On the other hand, there were interviewees who did not experience the chatbot communication as easy. This was particularly the case when the chatbot did not understand and answer their questions. This led to quite some frustrations. In addition, both groups outlined some difficulties in the interaction, albeit slightly different ones. In the older group, some interviewees said that too much information was given at once: too much information was provided in a single response, or too many answers or links were provided at the same time. Interviewees in the younger group also experienced this problem, and also noted that the navigation was inconvenient at times (particularly because of toggling between several screens). They also mentioned that it was not clear how to type: They were trying to find out which way they needed to formulated their questions in order for the bot to understand them. Lastly, there were some roadblocks to get to the chatbot, either because the chatbot was difficult to find or because personal information had to be filled out before starting the chat.

Table 2. Perceived ease of use of chatbots for customer service

\begin{tabular}{|c|c|c|}
\hline & Older adults & Younger adults \\
\hline \multicolumn{3}{|l|}{ Easy } \\
\hline Clear how it works & $\begin{array}{l}n=5 \\
\text { "There is absolutely no misunder- } \\
\text { standing of what I was doing or } \\
\text { challenge. I guess it was clear } \\
\text { very clear" (P8, } 60 \text { years) }\end{array}$ & $\begin{array}{l}n=3 \\
\text { "I find it to be easy. Just because it's pretty } \\
\text { straightforward. Once you click on the link } \\
\text { it takes you right there. And all you have to } \\
\text { do is your name and your email address } \\
\text { and make your question" (P4, 30 years) }\end{array}$ \\
\hline
\end{tabular}




\begin{tabular}{|c|c|c|}
\hline Smooth interaction & $\begin{array}{l}n=1 \\
\text { "Sometimes you can get into tech } \\
\text { support that's run by someone } \\
\text { who is using English as a second } \\
\text { language and it can } \\
\text { get complicated fairly quickly. } \\
\text { This seems to be very.. it's well } \\
\text { written" (P10, } 62 \text { years) }\end{array}$ & $\begin{array}{l}n=4 \\
\text { "It was so easy for me, just to type in a } \\
\text { few things, it was almost like talking to my } \\
\text { wife" (P5, 29 years) } \\
\text { "It was like back in the day when we used } \\
\text { aim [AOL Instant Messenger] (P7, } 27 \\
\text { years) } \\
\text { "I think that part of it has to do with like } \\
\text { the real time feedback. So it was like } \\
\text { continue to ask me like 'does this give you } \\
\text { the information that you needed'. Like 'are } \\
\text { you satisfied with this information?"' (P6, } \\
29 \text { years) }\end{array}$ \\
\hline $\begin{array}{l}\text { Preloaded options to } \\
\text { choose from }\end{array}$ & $\begin{array}{l}n=1 \\
\text { "So do you find having options } \\
\text { laid out beforehand helpful?" } \\
\text { "Yes [...] So to give me the option } \\
\text { to find my solution without going } \\
\text { all over the place" (P8, } 60 \text { years) }\end{array}$ & $\begin{array}{l}n=4 \\
\text { "It was pretty easy because actually the } \\
\text { way like after you say from where you } \\
\text { want to depart, it like gives you options so } \\
\text { you can like choose" (P1, 28 years) }\end{array}$ \\
\hline \multicolumn{3}{|l|}{ Not easy } \\
\hline $\begin{array}{l}\text { Chatbot did not answer } \\
\text { the question }\end{array}$ & $\begin{array}{l}n=4 \\
\text { "It had no f@cking clue what I } \\
\text { needed or wanted" (P13,54 years) }\end{array}$ & $\begin{array}{l}n=4 \\
\text { "I'm frustrated, I am feeling like what the } \\
\text { hell you guys (P7, } 27 \text { years) }\end{array}$ \\
\hline $\begin{array}{l}\text { Unclarities in the inter- } \\
\text { action }\end{array}$ & $\begin{array}{l}n=4 \\
\text { "I think they try to combine too } \\
\text { many steps into you know per } \\
\text { response" ( P9, } 67 \text { years) }\end{array}$ & $\begin{array}{l}n=6 \\
\text { "I would remove all the links here because } \\
\text { it's a little confusing" (P7, 27 years) } \\
\text { "It kept toggling back and forth between } \\
\text { several screens, confusing" (P6, 29 years) } \\
\text { "I was framing or phrasing the sentences in } \\
\text { a way that I thought that the chatbot could } \\
\text { read it" (P5, } 29 \text { years) }\end{array}$ \\
\hline $\begin{array}{l}\text { Roadblocks to get to } \\
\text { the chatbot }\end{array}$ & $\begin{array}{l}n=1 \\
\text { "It was a little complex because I } \\
\text { couldn't find her right away" } \\
(\mathrm{P} 14,59 \text { years })\end{array}$ & $\begin{array}{l}n=3 \\
\text { "Is it something that you use weekly or } \\
\text { monthly?" "No. First because it's not that } \\
\text { easy to find chatbots" (P2, } 30 \text { years) } \\
\text { "The part in the beginning where you are } \\
\text { required to put your name and stuff. [...] It } \\
\text { felt like an unnecessary roadblock to get to } \\
\text { the chat" (P6, } 29 \text { years) }\end{array}$ \\
\hline
\end{tabular}

Regarding perceived security, the overall finding was that interviewees in both groups had a difficult time assessing how secure the chatbot interaction actually was (see Table 3). They either concluded that they were unable to determine whether the chatbot was secure, or they just made the assumption that it was secure, or not.

Interviewees put forth only a few factors that they applied to guess how secure the communication was, and the two groups slightly differed in the factors that they mentioned. The older group did not mention any factors that led them to believe the chat- 
bot was secure. In the younger group a few interviewees thought the chatbot was secure because it did not ask for their personal information, or because it was the chatbot of a big company. In both groups, only a few interviewees mentioned factors that led them to believe the chatbot was not secure. One of the points mentioned was that if the chatbot cannot even understand or answer their question, they would not feel comfortable with entering their personal information. They also said that the informal interface and their guess that anybody in the company can read the conversation makes them believe the interaction is not secure.

Table 3. Perceived security of chatbots for customer service

\begin{tabular}{|c|c|c|}
\hline & Older adults & Younger adults \\
\hline \multicolumn{3}{|c|}{ Unable to determine whether chatbot is secure } \\
\hline & $n=2$ & $n=5$ \\
\hline & $\begin{array}{l}\text { "Is it secure? There is no way to } \\
\text { assess that" (P9, } 67 \text { years) }\end{array}$ & $\begin{array}{l}\text { "I don't know exactly what to think about } \\
\text { it" (P3, } 19 \text { years) }\end{array}$ \\
\hline \multicolumn{3}{|l|}{ Secure } \\
\hline $\begin{array}{l}\text { Assumption that it is } \\
\text { secure }\end{array}$ & $\begin{array}{l}n=3 \\
\text { "I'm not sure how secure it is. I } \\
\text { guess } 10 "(\mathrm{P} 11,65 \text { years })\end{array}$ & $\begin{array}{l}n=2 \\
\text { "9. I don't have any reason to assume it is } \\
\text { not secure" (P2, } 30 \text { years) }\end{array}$ \\
\hline $\begin{array}{l}\text { Because of how chatbot } \\
\text { deals with personal } \\
\text { information }\end{array}$ & $n=0$ & $\begin{array}{l}n=2 \\
\text { "9. They didn't ask for any of my personal } \\
\text { info" (P5, 29 years) }\end{array}$ \\
\hline $\begin{array}{l}\text { Because of company } \\
\text { perception }\end{array}$ & $n=0$ & $\begin{array}{l}n=1 \\
\text { "It's a big company, you just trust them" } \\
\text { (P3, 19 years) }\end{array}$ \\
\hline \multicolumn{3}{|l|}{ Not secure } \\
\hline $\begin{array}{l}\text { Assumption that it is } \\
\text { not secure }\end{array}$ & $n=0$ & $\begin{array}{l}n=1 \\
\text { "1. Just because these days }[\ldots] \text { people sell } \\
\text { your number and your credit card, I don't } \\
\text { trust it" (P7, 27 years })\end{array}$ \\
\hline $\begin{array}{l}\text { Because not intelligent } \\
\text { enough }\end{array}$ & $\begin{array}{l}n=1 \\
\text { "There's no way I would type in } \\
\text { my credit card information to a } \\
\text { chat where it doesn't even know } \\
\text { what I'm saying" (P13, } 54 \text { years) }\end{array}$ & $\begin{array}{l}n=1 \\
\text { "Lower, because I did not get the answer I } \\
\text { was looking for" (P2, } 30 \text { years) }\end{array}$ \\
\hline $\begin{array}{l}\text { Because of the informal } \\
\text { chat interface }\end{array}$ & $n=0$ & $\begin{array}{l}n=1 \\
\text { "I just feel like weird giving my infor- } \\
\text { mation to a chatbot [...].It's because of the } \\
\text { chat interface, giving the feeling of being } \\
\text { in like more of an unofficial space" (P6, } \\
29 \text { years) }\end{array}$ \\
\hline $\begin{array}{l}\text { Because company reads } \\
\text { the conversation }\end{array}$ & $\begin{array}{l}n=1 \\
\text { "Secure? } 0 . \text { Anybody that works } \\
\text { there can pull up that transcript } \\
\text { and see it" (P13,54 years) }\end{array}$ & $n=0$ \\
\hline
\end{tabular}




\section{Discussion}

In the discussion section, we first connect the findings regarding age differences in motivations and technology acceptance with the available literature, and suggest how to move ahead with research in these areas. Subsequently, we outline practical recommendations. Finally, we present limitations of the current study that also imply directions for future research.

\subsection{Age Differences in Motivations}

The first research question asked how older and younger adults differ in their motivations to use chatbots for customer service. In the interview study, the two age groups were aligned in their prime motivation: Customers use chatbots to get their (simple) customer queries answered in a fast and convenient manner. With that, our findings (in some cases quite literally) echo findings from previous qualitative research into experiences of chatbot communication [3,7]. It makes sense that these are the key reasons to use a chatbot in customer service, regardless of a customer's age.

However, the interviews did give the impression that the "human touch" (i.e., talking to somebody on the phone) may be more important for older segments of the population, whereas some younger adults actually used chatbot communication to avoid human contact. Interestingly, a quantitative survey among a representative sample of Dutch consumers aged 18-65 years found that age was not a significant predictor of usage, attitudes and satisfaction regarding brand chatbots, but that it was a predictor of the preference for human contact over a chatbot: Older respondents were more likely to express this preference [1].

Our study and these findings can be seen as a first step towards building a theory that helps explain how age groups (potentially) differ in their motivations to use chatbots. Especially the finding that age groups may differ in their preference of chatbot communication over human contact, or vice versa, requires further investigation. Before we can accurately interpret this result, we need further qualitative research that describes more in-depth how people compare chatbot communication with communication with live agents (and human-human communication more generally), and why they have a preference of one over the other. Only then, we can make statements about what could explain this potential age difference. Socioemotional selectivity theory (SST) [5] provided the theoretical impetus for the current study, and should still play a role in such future research. Possibly, the current finding is in line with the SST proposition that ageing individuals appreciate warm and meaningful social interactions more than younger adults. However, it seems reasonable to also consider other explanations -besides SST. An alternative explanation is the notion of media generations: Age groups also constitute different media generations that grew up with different media and thus differ in their attitudes toward those media [20]. The age difference in preference for human contact may be a reflection of the observation that the 
current younger generations are very familiar with communication through chat interfaces and consequently become more hesitant about talking to people on the phone (potentially experiencing phone anxiety). Only when qualitative research reveals more about the comparison between chatbot- versus human communication, can we formulate hypotheses to be tested in quantitative research. This should provide more insight in the extent to which age groups differ in their preferences for chatbot communication versus talking to human agents, and in the extent to which this is related to life-span development (as outlined by SST) or media generational differences.

\subsection{Age Differences in Technology Acceptance}

The second research question asked whether older and younger adults differ in perceived ease of use and perceived security of chatbots in customer service. In both age groups, there were participants for whom it was easy to communicate with chatbots, and both groups were also united in their frustrations when the bot did not understand and answer their queries. They were aligned as well in the difficulty they experienced in assessing the security of the chatbot. This latter finding is in contrast with a previous qualitative study in which the participants did not consider it challenging to reflect on trust in chatbots, and in which they reported stated or perceived security measures in chatbots to be important for trust [7]. In the current study, only a few participants mentioned factors that led them to believe the interaction was secure or not. There may be age differences here, but further qualitative research is required to delve into this more precisely. Subsequently, quantitative follow-up research is needed to assess whether the prevalence of such factors systematically differs between age groups. Such studies can use an extension of the Technology Acceptance Model [11] as framework, thus contributing to more fine-grained insight in differential chatbot perceptions between age groups.

\subsection{Practical Recommendations}

The interviews show that for both age groups it is essential that chatbots are answering the customer queries in a fast and correct way, thus avoiding customers' frustrations [see also 7]. The participants also found it confusing when too much information was provided at once, particularly when one was presented with several links or screens simultaneously. Older and younger adults may differ in the factors that contribute to (not so) easy experiences and perceived security, but further research is needed to further delve into these potential age differences. An aspect to take into special consideration is that older adults seem to differ from younger adults in their considerations regarding choosing a chatbot for customer service versus connecting to a live agent. Older adults possibly still value the human touch more, which would mean that relying on chatbot communication solely or predominantly can alienate older consumers whereas they constitute such a large share of the population [17]. 


\subsection{Limitations and Future Research}

The exploratory nature of this study and its sample composition need to be taken into account when drawing conclusions from this study. First, this study focuses on a subset of all possible perceptions of chatbot communication. Whereas we focused on motivations, perceived ease of use and perceived security, one could also expect age differences in perceptions on a more granular level. For instance, experimental studies found that older adults were more persuaded by a dominant (versus submissive) virtual agent whereas younger adults did not show this bias [16] and that older adults compared to younger adults- perceive such agents as more empathic when they show emotional nonverbal behaviors [10]. We aim to continue investigating how consumers of different ages experience chatbots as new types of communication partners [9], and we expect that -using SST as theoretical framework- age differences are particularly prevalent in responses to emotional and human-like cues in such communication.

Second, regarding sample composition, it is relevant to keep in mind that our older sample consisted of people aged 55 years and older. Although this is in line with previous and related research $[10,16], 55$ years is fairly young. Moreover, the age ranges in both groups were broad (19-30 years versus 54-81 years), whereas heterogeneity even increases as people age $[12,15,18]$. Therefore, we recommend future research to recognize that any age delineation of a sample is rather arbitrary, to use an older cut-off point than 55 years, and to pay more attention to subgroups within the ageing population. The quantitative survey among Dutch consumers identified particularly technology power usage (i.e., one's comfort with the adoption of new technology or gadgets) and online self-efficacy (i.e., one's assumptions about one's own level of ability to protect her or his data) as stronger predictors of usage, attitudes and satisfaction regarding brand chatbots than age [1], implying that particularly these two variables are important segmentation variables when aiming to identify subgroups within the ageing population.

Third, interviewees in our sample resided in the United States as well as in the Netherlands, but the current sample composition did not enable us to analyze whether cultural differences play a role in perceptions of chatbot communication. Such cultural differences should be explored in future research.

\section{References}

1. Araujo, T., ter Hoeven, C., van Zoonen, W.: Automated 1-2-1 communication. SWOCC Vol. 77. Stichting Wetenschappelijk Onderzoek Commerciële Communicatie (SWOCC), Amsterdam, the Netherlands (2019).

2. Araujo, T.: Living up to the chatbot hype: The influence of anthropomorphic design cues and communicative agency framing on conversational agent and company perceptions. Comput. Hum. Behav. 85, 183-189 (2018). https://doi.org/10.1016/j.chb.2018.03.051

3. Brandtzaeg, P.B., Følstad, A.: Why people use chatbots. In: Kompatsiaris, I., et al. (eds.) INSCI 2017. LNCS, vol. 10673, pp. 377-392. Springer, Cham (2017). https://doi.org/10.1007/978-3-319-70284-1_30 
4. Caine, K.E., O'Brien, M., Park, S., et al.: Understanding acceptance of high technology products: 50 years of research. In: Proceedings of the Human Factors and Ergonomics Society 50th Annual Meeting, pp. 2148-2152. Human Factors and Economics Society, Los Angeles, CA (2006).

5. Carstensen, L.L., Isaacowitz, D.M.,Charles, S.T.: Taking time seriously: A theory of socioemotional selectivity. American Psychologist 54(3), 165-181 (1999). https://doi.org/10.1037/0003-066X.54.3.165

6. Charmaz, K.: Constructing grounded theory: A practical guide through qualitative analysis. Sage, London (2006).

7. Følstad, A., Nordheim, C.B., Bjørkli, C.A.: What makes users trust a chatbot for customer service? An exploratory interview study. In: Bodrunova, S.S. (ed.) International Conference on Internet Science, pp. 194-208. Springer (2018). https://doi.org/10.1007/978-3-030-01437-7_16

8. Grimes, G.A., Hough, M.G., Mazur, E., Signorella, M.L.: Older adults' knowledge of internet hazards. Educational Gerontology 36(3), 173-192 (2010). https://doi.org/ $10.1080 / 03601270903183065$

9. Guzman, A.L., Lewis, S.C.: Artificial intelligence and communication: A HumanMachine Communication research agenda. New Media \& Society (advance online publication) (2019). https://doi.org/10.1177/1461444819858691

10. Hosseinpanah, A., Krämer, N.C., Straßmann, C.: Empathy for everyone? The effect of age when evaluating a virtual agent. In: Proceedings of the 6th International Conference on Human-Agent Interaction, pp. 184-190. ACM, Southampton, UK (2018). https://doi.org/10.1145/3284432.3284442

11. Marangunić, N.,Granić, A.: Technology acceptance model: A literature review from 1986 to 2013. In: Universal Access in the Information Society 14(1), 81-95 (2015). https://doi.org/ 10.1007/s10209-014-0348-1

12. Mares, M.L., Woodard, E.H.: In search of the older audience: Adult age differences in television viewing. Journal of Broadcasting \& Electronic Media 50(4), 595-614 (2006). https://doi.org/10.1207/s15506878jobem5004_2

13. Mature Marketing Association, https://www.themma.marketing/, last accessed 2019/09/08

14. Mitzner, T.L., Boron, J.B., Fausset, C.B., et al.: Older adults talk technology: Technology usage and attitudes. Comput. Hum. Behav. 26(6), 1710-1721 (2010). https://doi.org/10.1016/j.chb.2010.06.020

15. Moschis,G.P.: Consumer behavior over the life course. Springer, Cham, Switzerland (2019).

16. Rosenthal-von der Pütten, A.M., Straßmann, C., Yaghoubzadeh, R., Kopp, S., Krämer, N.C.: Dominant and submissive nonverbal behavior of virtual agents and its effects on evaluation and negotiation outcome in different age groups. Comput. Hum. Behav. 90, 397-409 (2019). https://doi.org/10.1016/j.chb.2018.08.047

17. United Nations, Department of Economic and Social Affairs, Population Division http://esa.un.org/wpp/, last accessed 2019/09/08

18. van der Goot, M.J., Beentjes, J.W.J., van Selm, M.: Older adults' television viewing as part of selection and compensation strategies. Communications: The European Journal of Communication Research 40(1), 93-111 (2015). https://doi.org/

10.1515/commun-2014-0025 
19. van der Goot, M.J., Bol, N., van Weert, J.C.M.: Translating socioemotional selectivity theory into persuasive communication: Conceptualizing and operationalizing emotionally-meaningful versus knowledge-related appeals. International Journal of Communication 13, 1416-1437 (2019).

20. van der Goot, M.J, Rozendaal, E., Opree, S.J., Ketelaar, P.E., Smit, E.G.: Media generations and their advertising attitudes and avoidance: A six-country comparison. Int. J. Advert. 37(2), 289-308 (2018).

https://doi.org/10.1080/02650487.2016.1240469 